\title{
ANÁLISE AMBIENTAL DA BACIA DO ARROIO CADENA, MUNICÍPIO DE SANTA MARIA -RS: VILA URLÂNDIA
}

Sandro S. Vargas de Cristo, Luís Eduardo de S. Robaina, Marcos G. Berger Departamento de Geociências -LAGEOLAM - CCNE UFSM - Santa Maria, RS

\section{RESUMO}

A vila Urlândia está incluída na bacia do arroio Cadena, e representa uma área da cidade de Santa Maria muito vulnerável à ação de processos geológicos, em especial, inundações e escorregamentos de margens de arroios. As edificações, em sua maioria, são residências de pequena área construída e materiais diversos, sem acabamento. As ruas não estão pavimentadas e não contam com rede de esgoto. Os esgotos domésticos, jogados diretamente nos arroios e o acúmulo de lixo são fatores de forte degradação ambiental. As inundações são os principais processo de risco na área. Outro processo de risco geológico, ocorre pelo desconfinamento das margens, provocados pela ação erosiva das águas fluviais sobre as margens e ação do escoamento das águas da chuva.

\section{ABSTRACT}

The Urlândia village is situated in the Cadena stream basin and it is an area of the city of Santa Maria vulnerable to geologic risk, mainly flood 
and mass-wasting on stream margin. The building, predominant are simple houses with small area and made up with diversity material. The street does not have paviment and sewerage. The domestic sewer and waste deposition direct in streams are factors causing of environmental degradation. The flood is principal risk in area. Another process of risk occurs because of the landslide of margin originate from stream flux and draining of water raining.

\section{INTRODUÇÃO}

A crescente ocupação urbana, sem critérios técnicos e em áreas sujeitas a ocorrência de processos geológicos, tem desencadeado o agravamento de situações de risco nos grandes centros urbanos e, até mesmo, nas cidades de médio e pequeno porte.

A possibilidade de prever a ocorrência de acidentes geológicos a partir da identificação e análise das áreas de risco, é fundamental para que sejam adotadas medidas que minimizem ou evitem danos e/ou perdas de vidas. Essas medidas podem estar representadas desde a remoção definitiva dos moradores das áreas sujeitas a risco até a eliminação ou redução dos riscos já instalados, através de alternativas que ofereçam melhorias de infraestrutura da ocupação e ações que impeçam o avanço da ocupação humana nessas áreas.

Santa Maria está geograficamente situada na região central do estado do Rio Grande do Sul, com uma população superior a 200 mil habitantes, dos quais cerca de $80 \%$ residem na área urbana. A ocorrência de áreas de risco são reconhecidas em diversas áreas do município (ROBAINA et alli, 1997; BERGER, M.G., 1999), mas é junto a bacia hidrográfica do Arroio Cadena que ocorrem os maiores problemas. A vila Urlândia está incluída nessa bacia e representa uma área da cidade muito vulnerável à 
ação de processos geológicos, em especial inundações e escorregamentos de margens. Situa-se na região sudoeste de Santa Maria (figura 1), delimitada pelos arroios Sanga do Hospital, Cadena e Cancela.

\section{METODOLOGIA}

Os trabalhos iniciaram com levantamento de informações sobre riscos ocorridos e compilação de mapas. Nos levantamentos foram quantificados os registros de eventos/acidentes (acidentes com perdas e danos) relacionados a inundação e escorregamentos, no período entre 19801995, para o município de Santa Maria, elaborado de acordo com uma pesquisa realizada junto ao jornal local (A RAZÃO), que forneceu informações dos principais riscos na região e os locais mais afetados. Como base cartográfica, utilizou-se a Planta da vila Urlândia, fornecida pela prefeitura municipal de Santa Maria, Diretoria de Planejamento Urbano, com escala 1:2.000.

Os trabalhos de campo desenvolveram-se por meio de visitas ao local, com observações do meio físico e do uso e ocupação do solo. Esses trabalhos, foram apoiados por observação aérea usando-se uma aeronave locada junto ao Aeroclube de Santa Maria para execução de um vôo panorâmico.

Os dados foram registrados fotograficamente e posteriormente cartografados, resultando na elaboração das cartas de uso e ocupação e de áreas de risco da vila Urlândia.

Para análise do uso e ocupação definiu-se três padrões de ocupação, baixo, médio e alto, com base nas características construtivas das moradias, dos serviços e infra-estrutura disponiveis. 


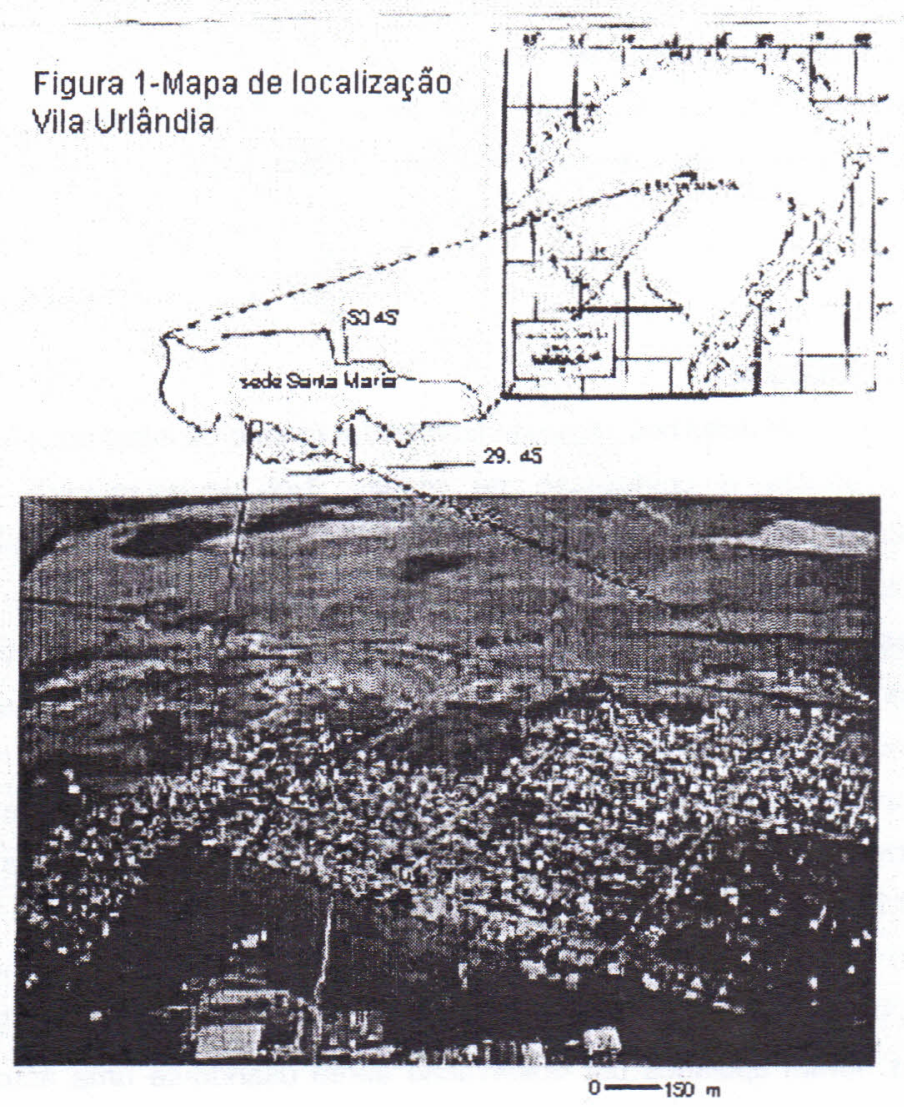

Figura 1 -Mapa de localização

\section{SINTESE HISTÓRICA DA OCUPAÇÃO DO MUNICÍPIO DE SANTA}

\section{MARIA}

Conforme BELÉM (1933), o município de Santa Maria surgiu de um acampamento de demarcadores dos limites territoriais em disputa entre Portugal e Espanha (Tratado de Santo Idelfonso de 1777, o qual estabelecia a demarcação de limites de terras entre Espanha e Portugal).

164 Rev. Ciência e Natura, Santa Maria, 22: 161 - 2000. 
Ainda segundo o autor, em 1857 Santa Maria foi elevada a categoria de Vila e no ano seguinte foi instalada a primeira câmara municipal da cidade. Nesta época, contava com aproximadamente 3.000 habitantes. Em 17 de maio de 1858, foi instalado o município de Santa Maria da Boca do Monte em função do acelerado crescimento populacional da época (desmembrado do município de Cachoeira do Sul). Três anos após a cidade sedia o mais importante dos comandos de Cavalaria da Guarda Nacional de Santa Maria (Guarnição Militar). É neste mesmo ano (1861) que o agrimensor Otto Brinckmann, a pedido dos governantes locais confeccionou a primeira planta da cidade de Santa Maria.

A partir de 1940, Santa Maria passou pôr intenso processo de urbanização, feito à base da transferência do homem do campo para a cidade. Em conseqüência, aceleraram-se os problemas de infra-estrutura e serviços urbanos, pois estes se tornaram insuficientes para acompanhar o crescimento populacional, tornando-se os mesmos seletivos (ROSA, 1982).

A ocupação da área na qual se encontra a atual vila Urlândia, segundo dados obtidos junto a Prefeitura Municipal de Santa Maria e, relatos de moradores antigos do local, teve inicio pôr volta do ano de 1958, quando a área foi loteada pelo então proprietário na época o senhor Carlos Hur, mas o processo de ocupação se intensificou a partir do ano de 1963, quando a área começou a ser habitada realmente.

Este processo de ocupação, desenvolveu-se primeiramente na rua Alfredo Viana, paralela ao arroio Cadena em toda sua extensão e, após a ocupação ramificou-se de forma intensa e desordenada para toda área ocupada atualmente. Provavelmente, os fatores como a especulação imobiliária nas áreas mais centrais da cidade e, também, a possibilidade de servirem como mão de obra as olarias locais, levaram o avanço da ocupação da região. 


\section{ASPECTOS GERAIS DA ÁREA}

O arroio Cadena, principal afluente que banha a Vila Urlândia, apresenta suas nascentes nas encostas abruptas do Planalto Sul-brasileiro, ao norte e no topo de colinas da Depressão Periférica a leste e oeste, definindo seu fundo de vale inicialmente no sentido leste-oeste e a partir do seu curso médio no sentido sul.

Nos arroios aparecem depósitos fluviais de idade geológica recente. Os depósitos são compostos por sedimentos arenosos de cor geralmente cinza. Os aluviões recobrem as formações Caturrita, Santa Maria e Rosário do Sul, que representam uma seqüência de siltitos argilosos a arenitos.

Ocorre ao norte, na em algumas nascentes, terrenos bastante íngremes ( $47 \%$ de declividade), mas na maioria os cursos d'água drenam áreas baixas pouco acidentadas ( $5 \%$ e $12 \%)$, formando um relevo de colinas, uma característica da Vila Urlândia, esta está inserida em uma região com cotas altimétricas variando de 60 a 80 metros, possuindo grande concentração de água, na forma de alagados e banhados, que outrora e, em alguns locais, ainda hoje, eram usados para a retirada de sedimentos que são a matéria prima para abastecer algumas olarias.

Segundo MACIEL FILHO (1991), uma grande parte da vila Urlândia está localizada em áreas desfavoráveis a ocupação urbana, por se tratar de áreas inundáveis e mal drenadas.

O arroio Cadena, o principal arroio limitante da vila, e seus afluentes os arroios Sanga do Hospital e Cancela captam água de grande parte da cidade, sofrendo um grande acúmulo de água pluvial. Além disso, a maior parte de seu curso encontra-se sem vegetação ciliar, que poderia auxiliar na proteção das margens.

Outra observação comum na área é a existência de depósitos clandestino de lixo ao longo das margens e no leito dos arroios. 


\section{CARACTERISTICA DA OCUPAÇÃO}

As edificações em sua maioria são residenciais térreas, de pequena área construída e materiais diversos. A análise da ocupação permitiu determinar suas características e definir a partir disso, três padrões, indicados como alto, médio e baixo (figura 2).

O alto padrão está representado por moradias com área construida igual ou superior a $80 \mathrm{~m}^{2}$, estando dominantemente associado às áreas topograficamente mais elevadas. Contam com ruas pavimentadas, esgoto pluvial e não estão em áreas de risco.

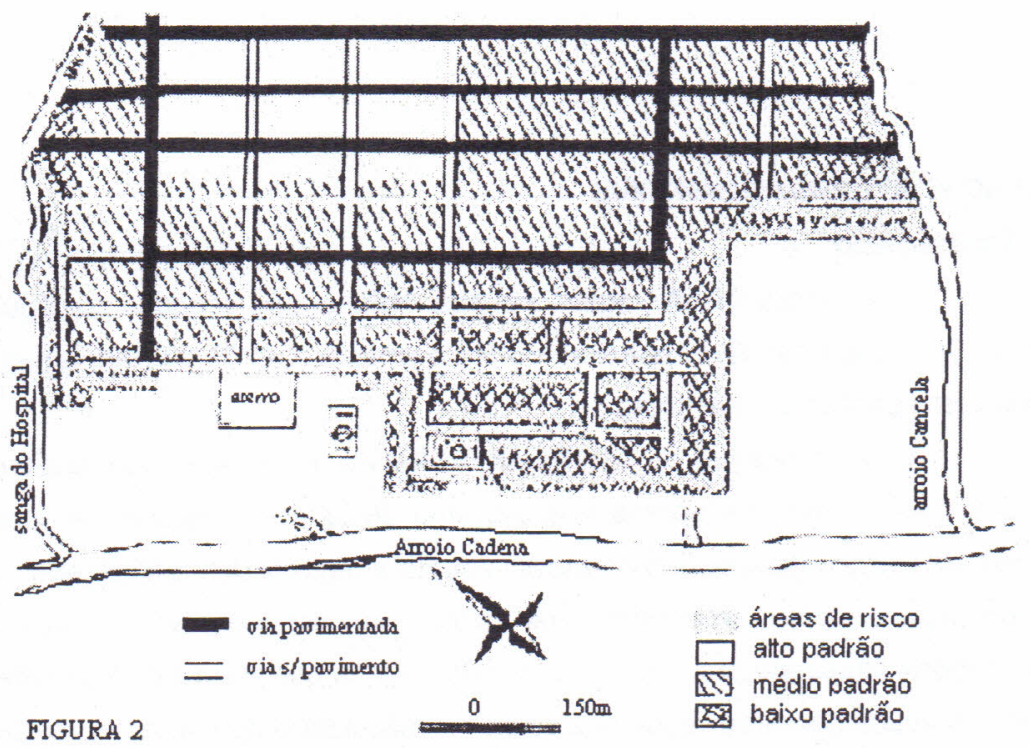

Figura 2 -Mapa de uso e ocupação

As moradias predominantes na Vila, apresentam um bom padrão construtivo, mas com acabamento não concluído. As ruas não estão pavimentadas e não contam com rede de esgoto. Essas feições foram 
definidas como médio padrão de ocupação. Representam uma população com uma certa capacidade de ações individuais para minimizar situações de risco. Em geral, não estão sujeitas a áreas de risco, a não ser junto a margem da Sanga do Hospital.

As moradias de baixo padrão estão representadas por construções que utilizam materiais de baixa qualidade, sem infra-estrutura e que tem avançado em direção às margens dos arroios e a várzea do Cadena. Em muitos casos, estas moradias se estabelecem muito próximas as regiões que ainda hoje são utilizadas para extração de argila.

\section{DIAGNÓSTICOS AMBIENTAIS}

\subsection{Saneamento}

As moradias da região, em sua maioria, são servidas por água tratada da Companhia Riograndense de Saneamento (CORSAN), em alguns casos com ligações clandestinas.

Com relação às condições sanitárias, os esgotos domésticos jogados diretamente nos arroios e o acumulo de lixo, são fatores de forte degradação ambiental. Quanto a rede de esgoto a maioria das edificações da vila despejam esgoto diretamente nos arroios, em especial, as ocupações das margens causando um odor desagradável e uma cor escura na água dos arroios. A pouca permeabilidade dos solos e a dificuldade de escoamento nas áreas mais baixas, pode ser evidenciado pelo acúmulo de água em valetas junto as vias (figura 3). Essas condições são propícias ao aparecimento de várias doenças na população residente. Com relação ao lixo, vários depósitos foram evidenciados sobre as margens dos arroios (Cadena, Cancela e Sanga do Hospital). Além de serem áreas onde proliferam animais nocivos, o lixo causa o entulhamento e barramento das drenagens, aumenta o peso (muito 
poroso) nas margens e auxiliam o encharcamento do solo.

Os canais artificiais construídos durante o período extrativo e os antigos barreiros profundos constituem-se em grave problema ambiental na área, principalmente pelo fato, das moradias estarem cada vez mais próximas. Nestas áreas ocorre a proliferação de insetos e, mais do que isso, são áreas que podem ocorrer afogamentos de crianças.

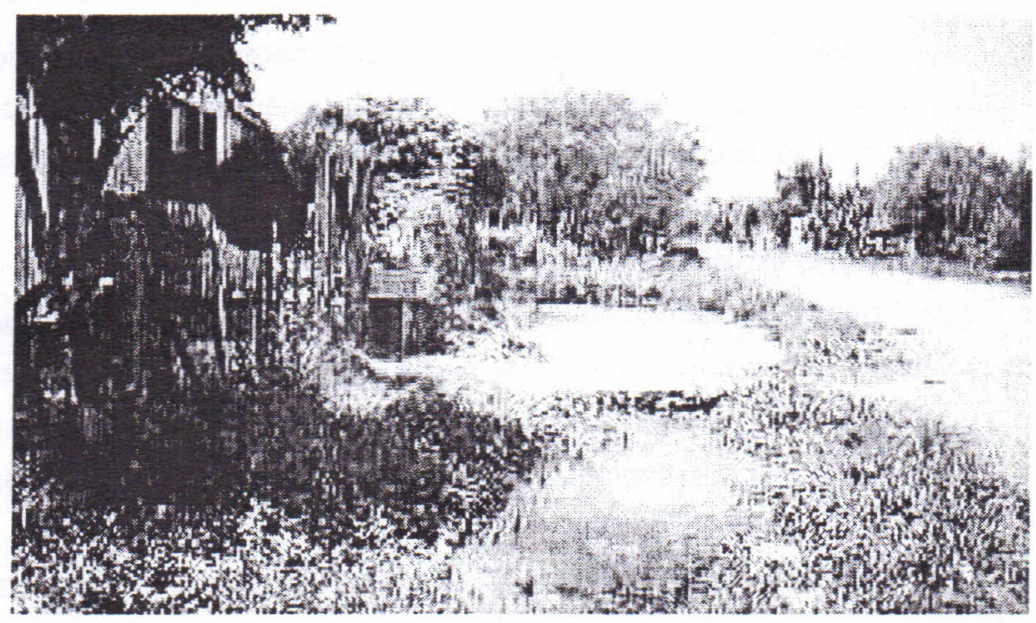

Figura 3. Acúmulo de água nas valetas junto as vias, regiões mais baixas da vila.

Outra questão, que preocupa, é o aterramento de áreas com entulho e lixo. Na vila Urlândia nota-se o aterramento de uma área localizada na planície de inundação do arroio Cadena, no qual estão sendo utilizados entulhos, em geral, misturados a lixo doméstico, o que poderá trazer problemas de engenharia, em caso de aproveitamento desta área para loteamento e edificação.

Rev. Ciência e Natura, Santa Maria, 22: 161 - 176 ,2000. 


\subsection{Avaliação de áreas de riscos geológicos}

Os processos relacionados ao risco na vila Urlândia, apresentam como fatores condicionantes principais: as características da ocupação junto a planície da inundação dos arroios Cadena, Cancela e Sanga do Hospital; o grau de degradação das margens das drenagens e; a ocorrência de chuvas intensas. As principais áreas de risco estão indicadas no mapa da figura 2.

As inundações ocorrem em várias porções da Vila, sendo o principal processo em atuação na área. Na porção noroeste, em específico na margem esquerda do arroio Sanga do Hospital, este processo acontece, principalmente, pela ocupação intensiva da margem. Este arroio também sofre com o grande acúmulo de lixo (resíduos sólidos) em suas margens e no seu próprio leito. O lixo colocado na área, incrementa o barramento (barreira que impede o fluxo normal das águas) em especial no local onde ocorre um cano metálico coletor de esgotos cloacais da cidade (utilizado pela CORSAN) que passa perpendicularmente ao canal principal do arroio (figura 4). Este fato aumenta as possibilidades de inundações das residências próximas, quando do transbordamento das águas do canal.

No setor oeste, onde está o arroio Cadena, o processo de inundação também é constante, causado por um somatório de fatores. Um deles é a ampla ocupação com tendência expansiva. Soma-se o assoreamento do canal com uma excessiva acumulação de sedimentos, que induz ao extravasamento do arroio.

Outro fator que incrementa as conseqüências das inundações, neste setor, é a presença de canais artificiais (figura 5), construídos em tempos passados, que tinham por finalidade escoar a água de antigos barreiros para o arroio Cadena.

Nos barreiros desativados, estes canais atuam como áreas de escape da água do próprio arroio, nos períodos em que as águas sobem, o 
que causa a inundação de parte da Vila localizada nas proximidades (margem esquerda do arroio Cadena).

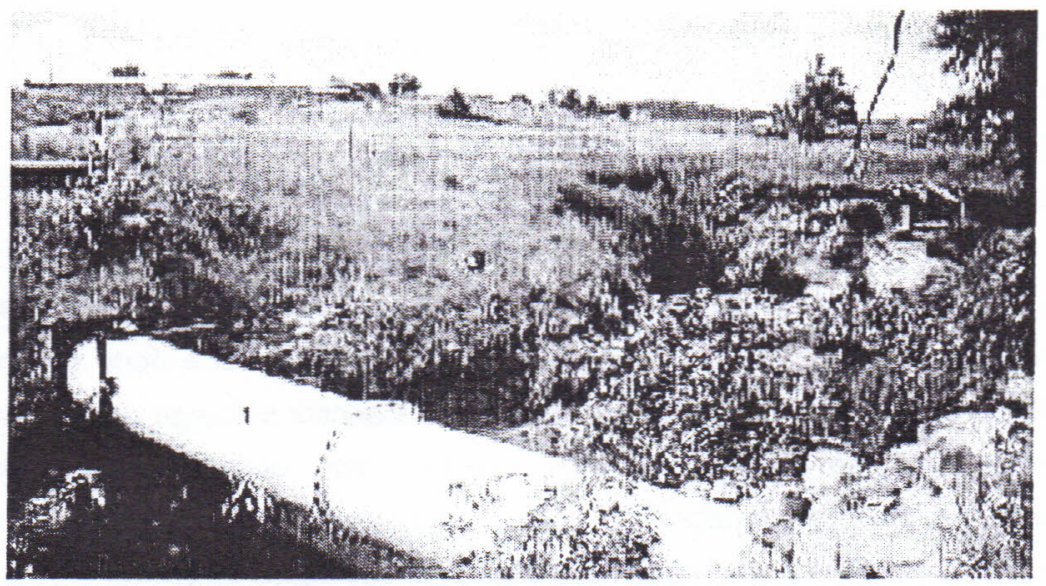

Figura 4: Barramento do Sanga do Hospital, pelo cano da CORSAN, lixo no leito do arroio e margens sem cobertura vegetal.

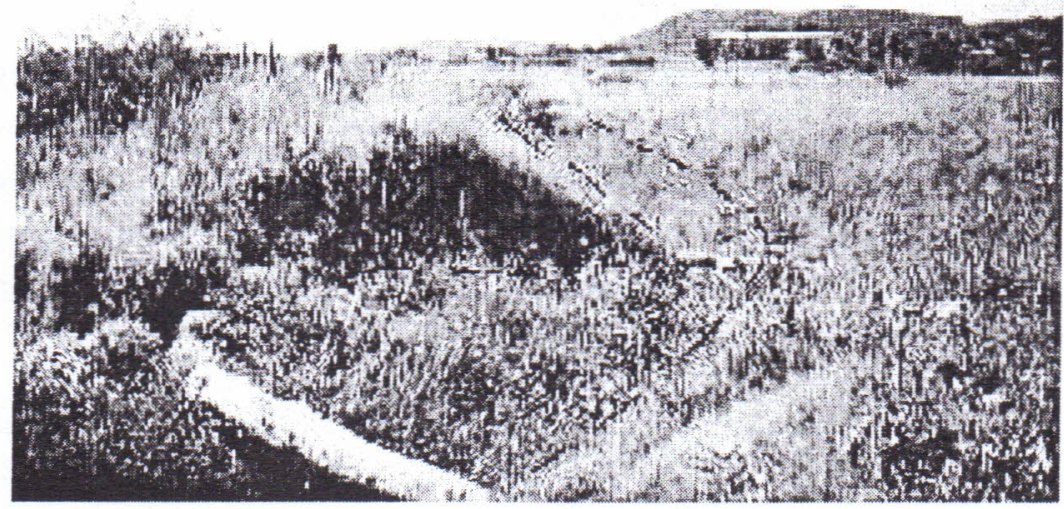

Figura 5. Canais artificiais que serviram como esgotamento de barreiros

Rev. Ciência e Natura, Santa Maria, 22: 161 - 2000. 
Na porção SW da vila Urlândia, área onde o arroio Cancela deságua no Cadena é a região onde estão concentrados os maiores problemas de inundação. Isso ocorre devido ao avanço da ocupação sobre a planície de inundação, a devastação da mata ciliar, a presença de vários depósitos de lixos sobre as margens e leitos dos arroios e, também, os canais artificias interferindo no regime fluvial dos arroios.

Outro processo de risco geológico, na região, está relacionado a movimentos de massa junto as margens dos arroios. Os escorregamentos de margens constatam-se, principalmente, nos setores sul e norte da área (figura 2), ou seja, nas margens dos arroios Cancela e Sanga do Hospital, respectivamente. Estes processos ocorrem pelo desconfinamento das margens, provocados pela ação erosiva do intenso fluxo das águas fluviais sobre as margens e, pela ação do escoamento das águas da chuva.

Os arroios encontram-se desprovidos de vegetação marginal (figura 6), o que facilita a ação do processos erosivos na área, pois a vegetação além de aumentar a capacidade de infiltração de água no solo, auxilia na prevenção dos escorregamentos de margens, através de suas raízes, contribuindo, também, na redistribuição das águas pluviais e no retardamento do escoamento superficial.

No setor norte da vila Urlândia (margem esquerda do Sanga do Hospital) é que aparece a situação mais delicada. É uma área de risco iminente onde várias residências estão sobre constante ameaça de escorregamento, com partes dos terrenos já desmoronados, casas apresentando rachaduras nas paredes, muros e árvores de grande porte, caem sobre o leito do arroio (figura 7). 


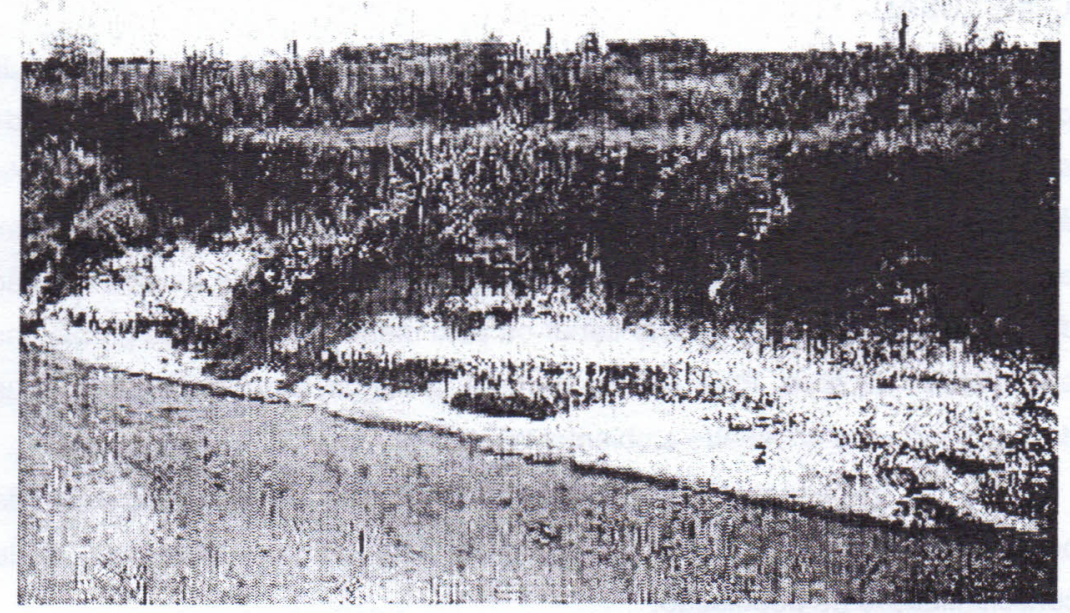

Figura 6: Assoreamento do arroio Cadena, margens arenosas e expostas.

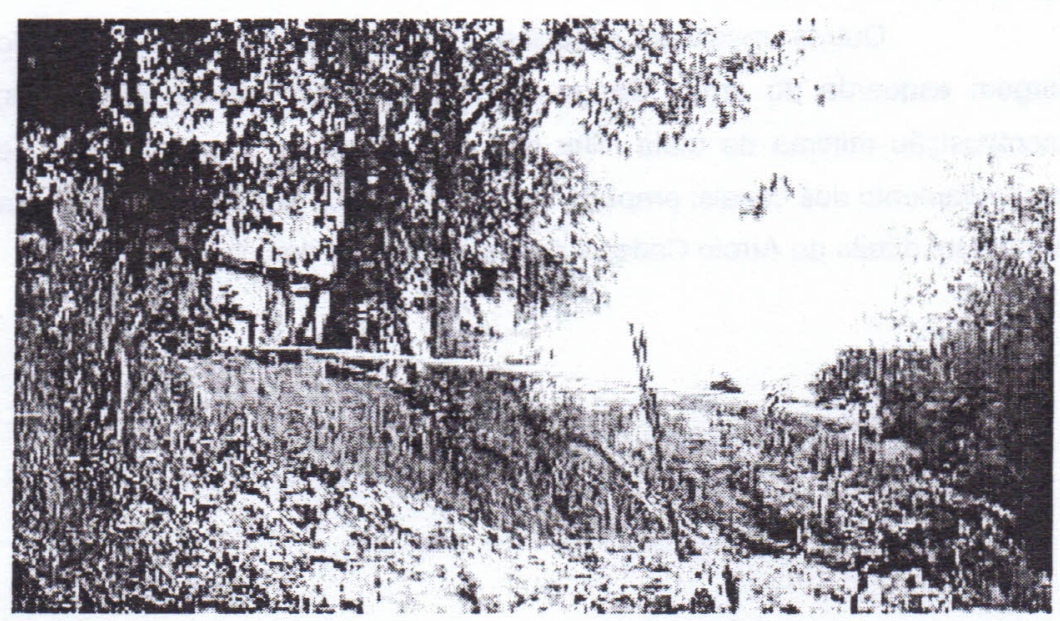

Figura 7: Escorregamento de margem no Sanga do Hospital, verifica-se que parte do terreno escorregou e lançamento de águas servidas diretamente no arroio.

Rev. Ciência e Natura, Santa Maria, 22: 161 - 176 ,2000. 


\section{CONCLUSÃO}

A Vila Urlândia sofre com vários problemas ambientais provocadas pelo avanço da ocupação, sem critérios técnicos, e a falta de ações do poder público que resgate a qualidade de vida dos moradores. As áreas de risco tendem a aumentar devido ao adensamento da ocupação, em especial de baixo padrão, junto a várzea e nas margens dos arroios. A ação do poder municipal deve buscar sanar ou pelo menos amenizar os problemas encontrados na área. Para isso, sugere-se, a seguir, algumas medidas que devem auxiliar da qualidade ambiental local.

É necessário estabelecer um processo de "congelamento" da ocupação através do desenvolvimento de campanhas educativas e de conscientização da população;

Concomitante ao processo de "congelamento", estabelecer uma negociação entre o poder público e a população buscando a regularização fundiária;

Outras medidas, associam-se a obras como: proteção da margem esquerda do arroio Sanga do Hospital com pedras imbricadas; recomposição mínima da mata ciliar das drenagens da área; dragagem e aprofundamento dos canais; preparar à jusante, junto a área militar localizada na margem direita do Arroio Cadena, locais de escape das cheias. 


\section{BIBLIOGRAFIA:}

AUGUSTO FILHO, O., CERRI,L.E.S., AMENOMORI, C.J. (1990). Risco Geológico: aspectos conceituais. In: Simpósio Latino-Americano Sobre Risco Geológico Urbano. São Paulo: ABGE, 1990:(1).p. 334341. Anais.

BELÉM, J. História do Município de Santa Maria - 1797 a 1933. Porto Alegre, Livraria Selbach, 1933.

BERGER, M. G. Inundações/Alagamentos na área Urbana de Santa Maria associado a ação antrópica e a distribuição das chuvas entre 1980 e 1995. Monografia de Graduação, UFSM, CCNE, Depto de Geociências. 1999. 80p

CERRI, L.da S. \& AMARAL, C.P. Riscos Geológicos In Geologia de Engenharia. São Paulo, ABGE, 1998., p.301-310.

INSTITUTO BRASILEIRO DE GEOGRAFIA E ESTATÍSTICA. Sinopse

Preliminar do censo Demográfico do Rio Grande do Sul. IX

Recenseamento Geral do Brasil -1980. Rio de Janeiro, IBGE, 1981. JORNAL A RAZÃO. Edições diárias em arquivo nos anos de 1980 a 1995.

Santa Maria, Rio Grande do Sul.

MACIEL FILHO, C. L. Carta Geotécnica de Santa Maria. Imprensa

Universitária, Santa Maria: UFSM, 1990. 22p

MORAES, A. S. Evolução Urbana de Santa Maria. Monografia de Especialização. Santa Maria. CCSH. UFSM - Faculdade de Filosofia, Ciências e Letras "Imaculada Conceição", 1982. 75p.

ROBAINA, L.E. de S.; BERGER,M.G. \& MEDEIROS, E.R. Estudos dos Riscos Geológicos na Região do Município de Santa Maria: O caso da Vila Bilibiu. In: Revista Ciência \& Natura, Santa Maria, Imprensa Universitária -UFSM, 1997: 19. P 173 -200. 
ROSA, S. B. da. Industrialização do município de Santa Maria. Monografia de Especialização, Santa Maria, CCSH. UFSM -Faculdade de Filosofia, Ciências e Letras "Imaculada Conceição", 1982. 80p.

SANTOS, M. A urbanização brasileira. Editora HUCTEC, São Paulo, 1996. 155p

176 Rev. Ciência e Natura, Santa Maria, 22: 161 - 2000. 